\title{
Treponema pallidum does not synthesise in vitro a capsule containing glycosaminoglycans or proteoglycans
}

\author{
R A StRUgnell,* C J HANDLEy,t D A LOWTHER,† S FAINE,* AND \\ S R GRAVES* \\ From the Departments of *Microbiology and †Biochemistry, Monash University, Clayton, Victoria, \\ Australia
}

SUMMARY Treponema pallidum was investigated for its ability to synthesise glycosaminoglycans or proteoglycans in vitro. Isolated viable $T$ pallidum organisms were incubated with radiolabelled precursors of glycosaminoglycans, sodium ${ }^{35} \mathrm{~S}$-sulphate and ${ }^{3} \mathrm{H}$-glucosamine (tritiated glucosamine). T pallidum failed to incorporate sodium ${ }^{35} \mathrm{~S}$-sulphate but did incorporate ${ }^{3} \mathrm{H}$-glucosamine into a macromolecule which may be associated with the surface of the treponeme. This macromolecule was resistant to degradation by specific glycosaminoglycanases. We conclude that $T$ pallidum does not synthesise a capsule containing glycosaminoglycans in vitro.

\section{Introduction}

Treponema pallidum freshly extracted from syphilitic rabbit testes possesses an outer layer which renders the organism refractory to interaction with antibody. ${ }^{1}$ Anionic material described as mucopolysaccharide has been observed by electron microscopy of treponemes stained with ruthenium red. ${ }^{23}$ The term mucopolysaccharide has been used to describe glycosaminoglycans as well as proteoglycans, and some mucins. Glycosaminoglycans are polyanionic macromolecules made up of repeating disaccharides which contain a hexosamine residue. There are four major classes of glycosaminoglycans; hyaluronic acid, chondroitin or chondroitin sulphates, keratan sulphate, and heparan sulphate or heparin. With the possible exception of hyaluronic acid, glycosaminoglycans are covalently linked to protein to form a class of macromolecules referred to as proteoglycan subunits. Some of these proteoglycan subunits are able to complex with hyaluronate to form proteoglycan aggregates or complexes. ${ }^{4}$

A possible interaction of glycosaminoglycans with the surface of $T$ pallidum has been suggested since freshly harvested organisms were agglutinated by lectins with high affinity for $\mathrm{N}$-acetylglucosamine and $\mathrm{N}$-acetylgalactosamine, ${ }^{5}$ indicating that these

Address for reprints: R A Strugnell, Department of Microbiology, Monash Medical School, Alfred Hospital, Prahran, Victoria, Australia 3181

Accepted for publication 2 May 1983 sugars may have been present in the treponemal capsule. This has lead investigators to postulate that $T$ pallidum synthesises an outer layer containing hyaluronic acid or chondroitin sulphate or both. ${ }^{16}$ An alternative explanation of the existence of this capsule might be that the treponemes adsorb host glycosaminoglycans to their surface. ${ }^{1}$

After infection with $T$ pallidum rabbit testes accumulate a mucoid substance which is rich in polyanionic material. ${ }^{6}$ Toluidine blue staining of testes and dermal lesions from syphilitic rabbits reveals metachromasia which can be removed with testicular hyaluronidase, ${ }^{7}$ an enzyme which degrades both chondroitin sulphate and hyaluronic acid. ${ }^{8}$ This indicates that these glycosaminoglycans may be involved in the orchitic process. ${ }^{7}$ While it has been suggested that the mucoid material may result from dissipation of the capsule synthesised by the treponeme, ${ }^{1}$ the glycosaminoglycans observed in infected testes and syphilitic serum may reflect increased host synthesis. 9

The aim of this study was to determine whether isolated $T$ pallidum has the capacity to synthesise in vitro a capsule containing proteoglycans or glycosaminoglycans. Samples of freshly harvested $T$ pallidum were incubated with radio labelled precursors of glycosaminoglycans, ${ }^{3} \mathrm{H}$-glucosamine (titrated glucosamine) and sodium ${ }^{35} \mathrm{~S}$-sulphate, ${ }^{10}$ and their incorporation into macromolecules was determined by gel filtration. The results are discussed in relation to the source of proteoglycans and glycosaminoglycans in syphilis. 


\section{Materials and methods}

Stocks of $T$ pallidum (Nichols strain) were maintained by testicular passage in sexually nature rabbits and by freezing in $15 \%$ glycerol stored at $-70^{\circ} \mathrm{C}$. The medium used throughout this study was RPMI 1640 with $1 \mathrm{mmol} / 1$ dithiothreitol, $5 \mathrm{mmol} / 1$ $\mathrm{N}$-2-Hydroxyethylpiperazine- $\mathrm{N}^{\prime}$-2-ethanesulphonic acid (HEPES), and $15 \%(\mathrm{v} / \mathrm{v})$ fetal calf serum (all from Flow, North Ryde, Australia).

\section{INCORPORATION OF RADIOLABELLED PRECURSORS OF GLYCOSAMINOGLYCANS INTO T PALLIDUM}

Viable $T$ pallidum organisms were extracted by the anaerobic method of Wong et al ${ }^{11}$ from orchitic rabbit testes which had been infected with $50 \times 10^{6}$ treponemes 10-12 days before. The extract was centrifuged at $1000 \times g$ for 10 minutes to remove most of the contaminating host cells. The treponemes in the supernatant were then concentrated by centrifugation at $10000 \times g$ for 30 minutes. $50 \times 10^{6}$ to $200 \times 10^{6}$ organisms were resuspended in $2 \mathrm{ml}$ fresh medium and labelled with $50 \mu \mathrm{Ci}$ ${ }^{3} \mathrm{H}$-glucosamine $(20-40 \mathrm{Ci} / \mathrm{mmol}$ Amersham International, Amersham, United Kingdom) or $100 \mu \mathrm{Ci} \mathrm{Na}{ }_{2}^{35} \mathrm{SO}_{4}(5 \mathrm{mCi} / \mu \mathrm{g} \mathrm{S}$, Amersham). Mean treponemal motility was measured by dark field examination and dropped from $100 \%$ to $80 \%$ during this labelling period. The treponemes were incubated with label for 24 hours at $34^{\circ} \mathrm{C}$ after which an equal volume of $8 \mathrm{~mol} / \mathrm{l}$ guanidine hydrochloride containing protease and testicular hyaluronidase inhibitors $(0 \cdot 2 \mathrm{~mol} / 1$ phenylmethylsulphonyl fluoride, $2 \mathrm{mmol} / \mathrm{l}$ benzamidine, $20 \mathrm{mmol} / 1 \mathrm{~N}$-ethyl maleamide, $0.1 \mathrm{~g} / \mathrm{l}$ soya bean trypsin inhibitor, $0 \cdot 2$ $\mathrm{mol} / \mathrm{l} \varepsilon$-amino caproic acid, $2 \mathrm{mmol} / 1 \mathrm{ferric}$ ion (all from Sigma)) was added. ${ }^{812}$ This yielded an extract with a final concentration of $4 \mathrm{mmol} / \mathrm{l}$ guanidine hydrochloride with inhibitors. Extraction was carried out at $4^{\circ} \mathrm{C}$ for 24 hours, when the samples were centrifuged at $10000 \times g$ for 30 minutes. The supernatant (guanidine extract) was collected and stored at $-20^{\circ} \mathrm{C}$. The pellet containing nonsolubilized $T$ pallidum was resuspended in $0.1 \mathrm{~mol} / 1$ acetate buffer (pH 5.5) containing $5 \mathrm{mmol} / 1$ ethylenediaminetetraacetic acid, $5 \mathrm{mmol} / \mathrm{l}$ cysteine hydrochloric acid and $2 \mathrm{~g} / \mathrm{l}$ papain (type IV, Sigma) and digested at $60^{\circ} \mathrm{C}$. After eight hours $2 \mathrm{~g} / 1$ fresh papain was added and the digestion continued for a further 12 hours. The digest (papain digest) was then collected and stored at $-20^{\circ} \mathrm{C}$.

MEASUREMENT OF AMOUNT OF RADIOLABEL INCORPORATED INTO MACROMOLECULES

The method of Stevens $e t$ al was used to measure the amount of incorporation of radiolabelled precursors into macromolecules. ${ }^{13}$ Samples of $200 \mu$ l of the guanidine extracts or papain digests were fractionated by gel filtration on Sephadex G-25 using PD-10 columns (Pharmacia) and equilibrated with $4 \mathrm{~mol} / \mathrm{l}$ guanidine hydrochloride, $0.1 \mathrm{~mol} / \mathrm{l}$ sodium sulphate, $0.05 \mathrm{~mol} / \mathrm{l}$ sodium acetate and $0.1 \%$ Triton X-100 (Sigma) (pH 5-8). The macromolecular fractions were collected and counted in a scintillation mixture containing $50 \%(\mathrm{v} / \mathrm{v})$ Triton X-100, 50\% toluene and $0.8 \%$ 2,5-diphenyloxazole.

\section{GEL FILTRATION OF MACROMOLECULES}

LABELLED WITH TRITIATED GLUCOSAMINE

Guanidine extracts of $T$ pallidum labelled with ${ }^{3} \mathrm{H}$-glucosamine were fractionated by gel filtration on Sepharose CL-6B. The extracts were dialysed against $4 \mathrm{~mol} / \mathrm{l}$ guanidine hydrochloride to remove excess free label and a $1 \mathrm{ml}$ sample was fractionated on a Sepharose CL-6B column $(1 \times 90 \mathrm{~cm})$, equilibrated, and eluted at a flow rate of $6 \mathrm{ml} / \mathrm{hour}$ with $4 \mathrm{~mol} / \mathrm{l}$ guanidine hydrochloride, $0.1 \mathrm{~mol} / \mathrm{l}$ sodium sulphate, $0.05 \mathrm{~mol} / 1$ sodium acetate, and $0.1 \%$ Triton X-100 (pH 5.8). Fractions of $1.2 \mathrm{ml}$ were collected and analysed for radioactivity.

\section{ENZYMIC DIGESTION OF MACROMOLECULES}

LABELLED WITH TRITIATED GLUCOSAMINE

Samples for enzymic digestion were extracted from $T$ pallidum labelled with ${ }^{3} \mathrm{H}$-glucosamine using $4 \mathrm{~mol} / \mathrm{l}$ guanidine containing $1 \mathrm{mmol} / \mathrm{l}$ ferric ion to inhibit any endogenous hyaluronidase activity. ${ }^{8}$ These extracts were separated into macromolecular fractions on PD-10 columns using the guanidine hydrochloride buffer without Triton $X-100$. The macromolecular fractions were pooled and dialysed against 1 litre of $0.1 \mathrm{~mol} / 1$ TRIS-acetic acid buffer (pH 6.5) (for 48 hours at $4^{\circ} \mathrm{C}$ with 3 changes of buffer) before digestion with streptococcal hyaluronidase or against $0.1 \mathrm{~mol} / 1$ sodium acetate buffer $(\mathrm{pH} 8 \cdot 0)$ before digestion with chondroitinase ABC. Hyaluronic acid (type III-S from human umbilical cord, Sigma) at $1.5 \mathrm{~g} / 1$ was added to each sample as a substrate before enzyme analysis. Samples were digested at $22^{\circ} \mathrm{C}$ for 24 hours using 20 units/ml streptococcal hyaluronidase (EC 4221, Saikagaku Kogyo Co, Tokyo) or 23 units $/ \mathrm{ml}$ chondroitinase ABC (EC 4224) isolated from Proteus vulgaris (a gift from Dr H C Robinson, department of biochemistry, Monash University). Undigested and digested samples were fractionated on a Biogel P-4 (Biorad) column (approximately $1.5 \times 50 \mathrm{~cm}$ ), equilibrated, and eluted at a flow rate of $20 \mathrm{ml} / \mathrm{hr}$ with $0.1 \mathrm{~mol} / 1$ pyridine-hydrochloric acid buffer $(\mathrm{pH}$ 6.5). Each $2 \mathrm{ml}$ fraction was assayed for hexuronate by the method of Bitter and Muir $^{14}$ and for radioactivity. 


\section{Results}

INCORPORATION OF RADIOLABELLED

PRECURSORS OF GLYCOSAMINOGLYCANS

INTO MACROMOLECULES

The table shows that $T$ pallidum did not incorporate appreciable amounts of ${ }^{35} \mathrm{~S}$-sulphate into macromolecules in vitro. In seven incorporation experiments (data from three of which are shown) $T$

TABLE Incorporation of radiolabelled precursors of glucosaminoglycans into macromolecules by isolated $T$ pallidum

\begin{tabular}{|c|c|c|}
\hline & $\begin{array}{l}35 S \text {-sulphate } \\
\text { incorporation } \\
\text { (dpm/106 } \\
\text { T pallidum) }\end{array}$ & $\begin{array}{l}3 \mathrm{H} \text {-glucosamine } \\
\text { incorporation } \\
\text { (dpm/106 } \\
T \text { pallidum) (\%)* }\end{array}$ \\
\hline $\begin{array}{l}\text { Experiment } 1 \\
\text { guanidine extract } \\
\text { papain digest } \\
\text { total }\end{array}$ & $\begin{array}{l}<10 \\
<10 \\
<10\end{array}$ & $\begin{array}{rr}1826 & (98) \\
37 & (2) \\
1863 & (100)\end{array}$ \\
\hline $\begin{array}{l}\text { Experiment } 2 \\
\text { guanidine extract } \\
\text { papain digest } \\
\text { total }\end{array}$ & $\begin{array}{l}<10 \\
<10 \\
<10\end{array}$ & $\begin{array}{rr}1330 & (99) \\
18 & (1) \\
1348 & (100)\end{array}$ \\
\hline $\begin{array}{l}\text { Experiment } 3 \\
\text { guanidine extract } \\
\text { papain digest } \\
\text { total }\end{array}$ & $\begin{array}{l}<10 \\
<10 \\
<10\end{array}$ & $\begin{array}{r}1749(97) \\
59 \quad(3) \\
1808(100)\end{array}$ \\
\hline
\end{tabular}

$\mathrm{dpm}=$ disintegrations per minute (background levels of radioactivity $=<10 \mathrm{dpm})$.

*percentage of total radioactivity appearing in guanidine extract and papain digest. pallidum failed to incorporate ${ }^{35} \mathrm{~S}$-sulphate beyond expected background levels. This result indicates that $T$ pallidum does not synthesise in vitro a capsule containing sulphated glycosaminoglycans under the conditions employed. The organism did incorporate ${ }^{3} \mathrm{H}$-glucosamine, however, and a mean of $98 \%$ of the recovered macromolecular label was present in the guanidine extract.

\section{HYDRODYNAMIC SIZE OF MACROMOLECULES}

LABELLED WITH TRITIATED GLUCOSAMINE

The results from the incorporation experiments suggested that while $T$ pallidum did not synthesise a sulphated glycosaminoglycan in vitro it might produce hyaluronic acid, a non-sulphated glycosaminoglycan. Figure 1 shows homogeneity and hydrodynamic size of the ${ }^{3} \mathrm{H}$-glucosamine labelled macromolecules which were determined by gel filtration.

Fractionation of guanidine extracts on Sepharose CL-6B yielded a single peak with a Kav (diffusion coefficient) of $0 \cdot 55$. The radioactivity eluting at the total volume of the column was unincorporated ${ }^{3} \mathrm{H}$-glucosamine. If the macromolecule was hyaluronic acid then this Kav would correspond to a molecular weight of approximately 15000 daltons, ${ }^{15}$ which is within the range reported for hyaluronic acid. ${ }^{16}$ The susceptibility of this macromolecule to specific enzyme hydrolysis with streptococcal hyaluronidase and chondroitinase $\mathrm{ABC}$ was determined.

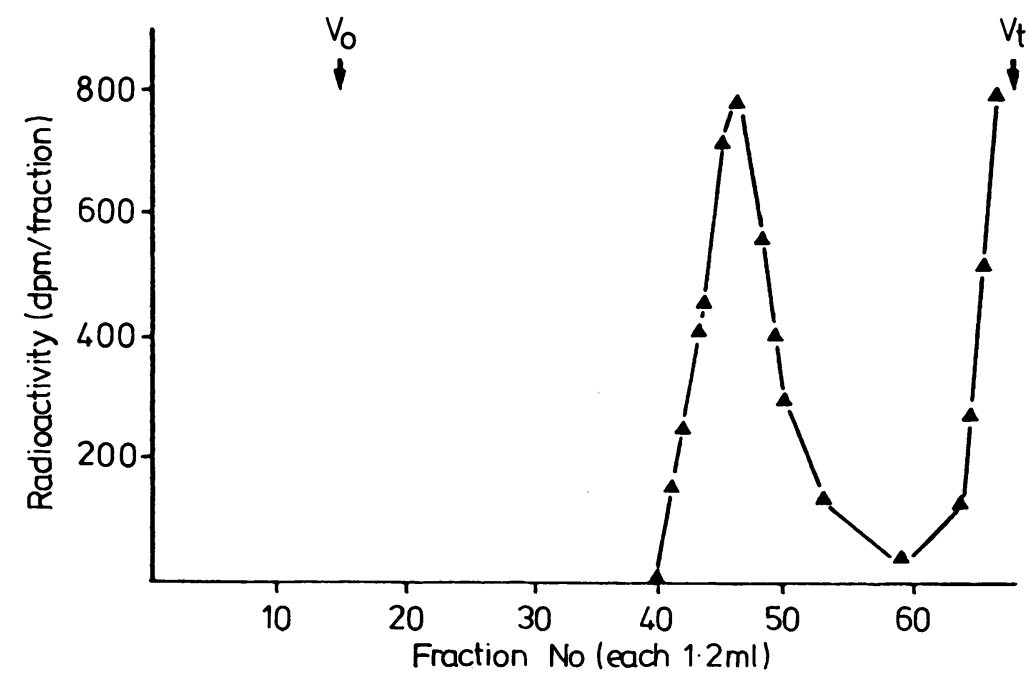

FIG 1 Distribution of ${ }^{3} \mathrm{H}$-glucosamine incorporation into macromolecules associated with $T$ pallidum after fractionation on Sepharose $C L-6 B(\mathrm{dpm}=$ disintegrations per minute; $\mathbf{\Delta}-\mathbf{\Delta}$ elution profile of guanidine extract of $T$ pallidum labelled with ${ }^{3} \mathrm{H}$-glucosamine). 
ENZYMIC DIGESTION OF MACROMOLECULES LABELLED WITH TRITIATED GLUCOSAMINE

Hyaluronic acid, a known substrate for both streptococcal hyaluronidase and chondroitinase $A B C,{ }^{17} 18$ was added to guanidine extracts of ${ }^{3} \mathrm{H}$-glucosamine labelled $T$ pallidum which had previously been dialysed against the required buffer. These samples were fractionated on a Biogel P-4 column (figs $2 a$ and $3 a$ ). Fractionation of the undigested labelled $T$ pallidum macromolecule and hyaluronic acid in the two buffer systems, pH 6.5 (fig 2a) and $\mathrm{pH} \mathrm{8.0} \mathrm{(fig} \mathrm{3a),} \mathrm{produced} \mathrm{similar} \mathrm{elution}$ profiles. The hyaluronic acid (assayed by hexuronate) and the ${ }^{3} \mathrm{H}$-glucosamine labelled $T$ pallidum macromolecule first eluted at the void volume. No hexuronate was detected in the guanidine extracts of $T$ pallidum before the addition of hyaluronic acid.

A sample of the ${ }^{3} \mathbf{H}$-glucosamine labelled macromolecule containing hyaluronic acid was digested-with streptococcal hyaluronidase and fractionated on Biogel P-4 (Fig 2b). Streptococcal hyaluronidase digestion of hyaluronic acid yields $\Delta-4,5$-unsaturated hexasaccharides and tetra-

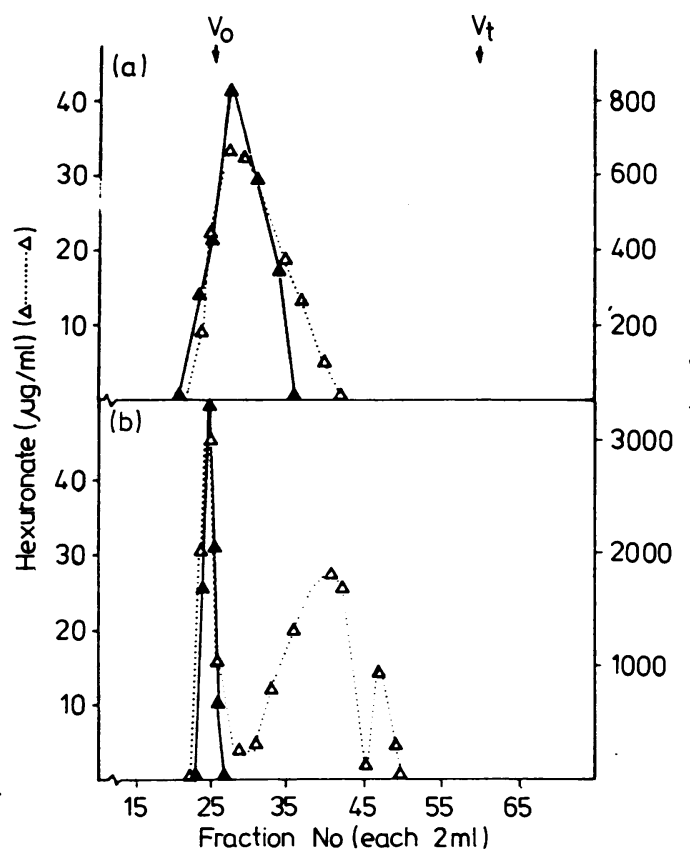

FIG 2 Separation on Biogel P-4 of ${ }^{3} \mathrm{H}$-glucosamine labelled macromolecule associated with $T$ pallidum (a) before (b) after digestion with streptococcal hyaluronidase $(\mathrm{dpm}=$ disintegrations per minute; elution profiles of $T$ pallidum macromolecules labelled with ${ }^{3} H$-glucosamine; $\Delta-\Delta$ elution profiles of hyaluronic acid, added as a specific control). saccharides. ${ }^{17}$ Two hexuronate peaks corresponding with these products are seen in Fig $2 \mathrm{~b}$. This result indicated that the added enzyme was active. The undigested material containing hexuronate appearing at the void volume represented chondroitin sulphate present in the hyaluronic acid preparation. Chondroitin sulphate was not digested by streptococcal hyaluronidase but was digested with chondroitinase ABC (Fig 3b). The ${ }^{3} \mathrm{H}$-glucosamine labelled macromolecule was not degraded by streptococcal hyaluronidase, which indicated that it was not hyaluronic acid.

No digestion of the ${ }^{3} \mathrm{H}$-glucosamine labelled macromolecule was observed with chondroitinase ABC (Fig 3b). Proof of enzyme activity was again observed as the hyaluronic acid present in the sample was almost totally degraded to disaccharide subunits. This result reinforced the evidence provided by ${ }^{35} \mathrm{~S}$-sulphate incorporation studies. Chondroitinase ABC degrades hyaluronic acid and all sulphated glycosaminoglycans except heparan sulphate. ${ }^{18} \mathrm{Had}$ heparan sulphate been present in the treponemal capsule, incorporation of ${ }^{35} \mathrm{~S}$-sulphate would have been expected.

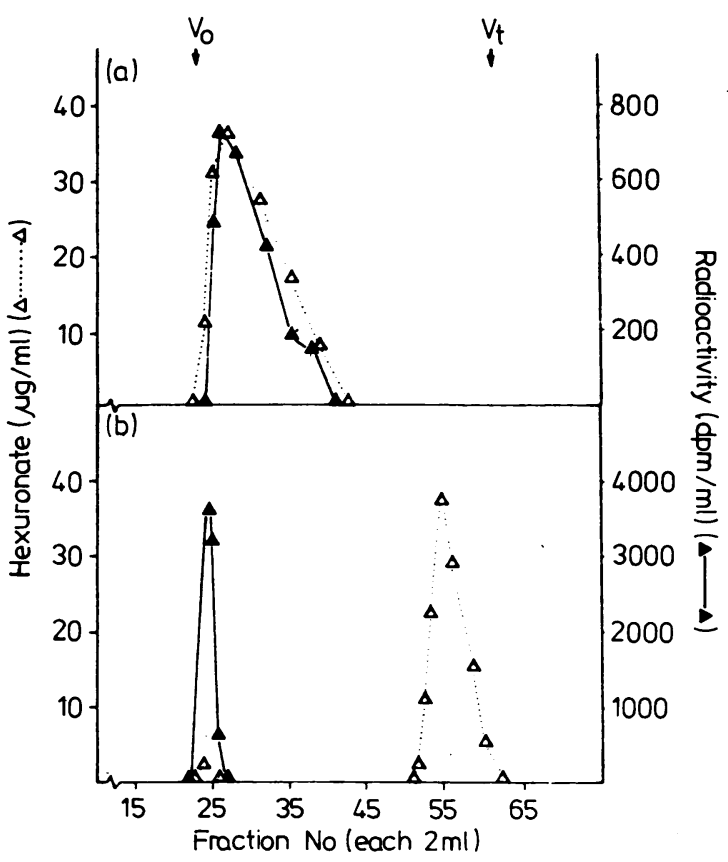

FIG 3 Separation on Biogel P-4 of H-glucosamine labelled macromolecule associated with $T$ pallidum (a) before and (b) after digestion with chondroitinase $A B C$ (dpm = disintegrations per minute; $\mathbf{\Delta} \mathbf{\Delta}=$ elution profiles of $T$ pallidum macromolecules labelled with ${ }^{3}$ H-glucosamine; $\Delta-\Delta$ elution profiles of hyaluronic acid, added as a specific control). 


\section{Discussion}

It has been suggested that $T$ pallidum may synthesise a capsule containing glyosaminoglycans, both in vivo and in vitro. ${ }^{15}$ The presence of this capsule could explain the organism's ability to evade host immune mechanisms, especially humoral responses, and to establish a latent infection. The chemical and physical heterogeneity as well as the polyanionic nature of glycosaminoglycans makes their identification difficult. The most sensitive and favoured technique available at present uses the susceptibility of these macromolecules to selective enzyme digestion. We were unable to detect synthesis of sulphated glycosaminoglycans or of hyaluronate by $T$ pallidum using such methods. Incorporation of glucosamine was observed, but the product was shown not to be a glycosaminoglycan because of its insensitivity to specific glycosaminoglycanases. A high proportion (mean 98\%) of the incorporating macromolecules was present in the guanidine extract. Guanidine hydrochloride $4 \mathrm{~mol} / 1$ is a denaturing solvent capable of breaking both hydrogen and ionic bonds but incapable of dissociating covalent bonds. ${ }^{12}$ The presence of the majority of the label in the guanidine extract suggests that the macromolecule is only loosely associated (either by hydrogen or ionic bonds) with $T$ pallidum and may be part of the treponemal capsule. It has been noted that the treponemal extracellular layer is degraded during extraction of the organism from infected rabbit testes, ${ }^{3}$ which suggests that it is only loosely associated with the surface of the treponeme. Preliminary evidence suggests that the product containing ${ }^{3} \mathrm{H}$-glucosamine may be a glycoprotein (unpublished data).

While the conditions employed in these experiments did not permit $T$ pallidum multiplication, there is no direct evidence to suggest that $T$ pallidum synthesises a capsule containing proteoglycans or glycosaminoglycans in vivo. Early investigators reported that cutaneous syphilomas from rabbits treated with cortisone contained 18 times more treponemes but only four times more hyaluronic acid or material like it (it was not stated how the assay for hyaluronate was performed) than did syphilomas from untreated rabbits. ${ }^{6}$ Electron microscopy of ruthenium red stained treponemes has shown surface staining only ${ }^{3}$; such staining is representative of polyanions, which include glycoproteins as well as glycosaminoglycans.

It is likely that $T$ pallidum, if it does possess a capsule containing proteoglycans or glycosaminoglycans, has adsorbed to its surface proteoglycans or glycosaminoglycans derived from the host rather than having synthesised these molecules itself. $T$ pallidum has been shown to bind a number of host glycoproteins and proteins including transferrin and albumin to its surface. ${ }^{19}$ During the development of orchitis molecules like glycosaminoglycans are certainly present in the mucoid material which accumulates in the testes, ${ }^{90}$ and glycosaminoglycans have been detected in the serum of infected rabbits. ${ }^{9}$ If $T$ pallidum possessed a lectin capable of binding host synthesised sulphated glycosaminoglycans to its surface the presence of a capsule of host origin would be explained. Similar lectin interactions with host derived macromolecules have been reported in other infectious diseases, including schistosomiasis. ${ }^{21}$ During these enzyme studies it was noted that the added hyaluronic acid and the incorporating treponemal macromolecule coeluted over 20 fractions in undigested samples (see Figs $2 a$ and 3a). This coelution may represent the phenomenon associated with gel filtration of viscous samples 22 or reflect an association between the labelled $T$ pallidum macromolecule and the glycosaminoglycans hyaluronic acid or chondroitin sulphate (which was found to contaminate the hyaluronate).

It is not known why syphilitic rabbits increase their synthesis of glycosaminoglycans. It may be a response to tissue injury resulting from the toxic moeity of $T$ pallidum, ${ }^{23}{ }^{24}$ or to the action of the treponemal glycosaminoglycanase on the host tissues, which could increase turnover of the connective tissue matrix at the site of infection. ${ }^{25}$ Accelerated synthesis by connective tissue in response to other glycosidases has been observed. ${ }^{26}$

Further research is required to determine the basis of host glycosaminoglycan synthesis, how it is stimulated by $T$ pallidum infection, and the mechanism of binding these molecules to the treponemal surface.

We thank Ms L Drummond for her excellent technical assistance. Financial support for this work was provided by the Australian National Health and Medical Research Council, the Utah Foundation, and Monash University.

References

1. Fitzgerald TJ. Pathogenesis and immunology of Treponema pallidum. Annu Rev Microbiol 1981;35:29-54.

2. Fitzgerald TJ, Cleveland $P$, Johnson RC, Miller JN, Sykes JA Scanning electron microscopy of Treponema pallidum (Nichols strain) attached to cultured mammalian cells. $J$ Bacteriol 1977; 130: 1333-4.

3. Zeigler JA, Jones AM, Jones RH, Kubica KM.. Demonstration of extracellular material at the surface of pathogenic $T$ pallidum cells. Br J Vener Dis 1976;52:1-8.

4. Muir H, Hardingham TE. Structure of proteoglycans. In: Whelan WJ, ed. MTP International Review of Science (Biochemistry Series I) Biochemistry of carbohydrates. London: Butterworth 1975;5:153-222. 
5. Fitzgerald TJ, Johnson RC. Surface mucopolysaccharides of Treponema pallidum. Infect Immun 1979;24:244-51.

6. Turner TB, Hollander DH. Biology of the treponematoses. In: WHO monograph series No 35. Geneva: World Health Organization 1957.

7. Scott V, Dammin GJ. Morphologic and histochemical sequences in syphilitic and in tuberculous orchitis in the rabbit. American Journal of Syphilis, Gonorrhea and Venereal Diseases 1954;38: 189-202.

8. Mathews MB. Aminal mucopolysaccharidases. In: Neufeld EF, Ginsburg V, eds. Methods in Enzymology. New York: Academic Press, 1966; 8: 654-63.

9. Baughn RE, Musher DM. Reappraisal of lymphocyte responsiveness to concanavalin A during experimental syphilis: evidence that glycosaminoglycans in the sera and tissues interfere with active binding sites on the lectin and not with the lymphocytes. Infect Immun 1982; 35: 552-9.

10. Roden L, Schwartz N. Biosynthesis of connective tissue proteoglycans, In: Whelan WJ, ed. MTP International Review of Science (Biochemistry Series 1) Biochemistry of carbohydrates. London: Butterworth, 1975;5:95-182.

11. Wong GHW, Steiner BM, Graves SR. Effects of anaerobic and microaerophilic conditions of extraction and incubation on the survival of Treponema pallidum in vitro. Br J Vener Dis 1981;58: 139-42.

12. Hascall VC, Kimura JH. Proteoglycans: isolation and characterization. In: Cunningham LW, Fredericksen DW, eds. Methods in Enzymology. New York: Academic Press, 1982; 82:769-800.

13. Stevens RL, Nissley SP, Kimura JH, Rechler MM, Caplan AI, Hascall VC. Effects of insulin and multiplication-stimulating activity on proteoglycan biosynthesis in chondrocytes from the Swarm rat chondrosarcoma. J Biol Chem 1981; 256:2045-52.

14. Bitter T, Muir HM. A modified uronic carbazole reaction. Anal Biochem 1962;4:330-4.
15. Wasterson A. A method for the determination of the molecular weight and molecular weight distribution of chondroitin sulphate. J Chromatogr 1971;59;87-97.

16. Lindahl U, Höb M. Glycosaminoglycans and their binding to biological macromolecules. Ann Rev Biochem 1978;47: 385-417.

17. Ohya T, Kaneko Y. Novel hyaluronidase from streptomyces Biochim Biophys Acta 1970; 198:607-9.

18. Yamagata T, Saito H, Habuchi O, Suzuki S. Purification and properties of bacterial chondroitinases and chondrosulphatases. J Biol Chem 1968; 234: 1523-35.

19. Alderete JF, Baseman JB. Surface associated host proteins on virulent Treponema pallidum. Infect Immun 1979; 26: 1048-56.

20. Turner TB. Syphilis and the treponematoses. In: Mudd S, ed. Infectious agents and host reactions. Philadelphia: WB Saunders, 1970; 346-90.

21. Sher A, Moser G. Schistosomiasis: immunologic properties of the developing schistosomula. Am J Path 1981; 102: 121-6.

22. Gel Filtration, theory, and practice. Handbook. Uppsala, Sweden: Pharmacia Fine Chemicals, 1981.

23. Oakes SG, Repesh LA, Pozos RS, Fitzgerald TJ. Electrophysiological dysfunction and cellular disruption of sensory neurones during incubation with Treponema pallidum. $\mathrm{Br} J$ Vener Dis 1982;58:220-7.

24. Wong GHW, Steiner B, Graves S. Inhibition of macromolecular synthesis in cultured rabbit cells by Treponema pallidum. Infect Immun 1983;41;636-43.

25. Fitzgerald TJ, Johnson RC. Mucopolysaccharidase of Treponema pallidum. Infect Immun 1979;24:261-8.

26. Fitton-Jackson S. Environmental control of macromolecular synthesis in cartilage and bone morphogenetic response to hyaluronidase. Proc $R$ Soc Lond [Biol] 1970;175:405-53. 